most natural, comprehensive, useful, important and effective taxonomic unit applicable to all groups. It is probably also the unit - the genus being most simply defined as a group of related species-of greatest use to the non-taxonomic botanist.

In his discussion of the difficulties of generic delimitation, Dr. Lawrence considers that taxonomists must function as synthesizers, and bring to bear on each problem all relevant data from related fields of botanical study. He also suggests a number of practical steps which may be taken to achieve this desirable end. Dr. Bailey considers that it is essential to determine what contributions anatomy can actually make to taxonomy, since some characters that appear to be relatively stable in some groups may be highly plastic in others; that is, internal characters are inherently no more reliable than external ones. One of his conclusions is that, because the anatomical approach is so time-consuming, it should in the main be reserved for those specially difficult problems where the significance of the results is likely to justify the effort expended. The anatomical approach to taxonomy has been especially rewarding in certain groups, in particular in certain ancient and primitive woody dicotyledons. Dr. Eames points out that, in taxonomic and phylogenetic studies, the internal structures of the flower are just as valuable as, and, in some instances, for example, where parts are vestigial, may be even more valuable than, the external form. But the evaluation of internal floral structures, as evidence of natural relationships, requires a wide knowledge of this field of observation and an awareness of the prevalence of evolutionary parallelisms and convergences. At the generic level, groups of floral anatomical characters, and even some rather specific ones, may be surprisingly well defined. Dr. Eames gives many interesting examples of the application of floral anatomy to problems of taxonomy; in the Ranunculaceae, for example, which has long been regarded as a "very natural family", the anatomical evidence yields a quite contrary view, and indicates that some of the included genera should be raised to family status. This illustrates the critical importance of the combined taxonomic and anatomical approach.

In a critical discussion of the cytogenetical contribution to the delimitation of genera, Dr. R. C. Rollins makes the point that, in determining the nature and limits of a particular genus, it is not a question that the investigation must be done at the generic level or not at all : rather, the interest should centre on the relatedness of the species involved; and it is here especially that cytogenetics can make an important and, in some instances, essential contribution. Examples are cited where the genetical evidence has pointed the way to the correct generic placing of previously intractable species ; but because of the time involved, genetical studies can only be directed towards especially favourable groups.

The value of a knowledge of chromosome numbers in taxonomy is critically considered and the use and limitations of the data assessed. Chromosome number affords valuable evidence for taxonomic purposes in some instances but not in others. Where the chromosome number is constant within a genus, a useful test is available for the inclusion or exclusion of a species where doubt as to its affinity exists; on the other hand, if both aneuploidy and polyploidy occur within a genus, the cytological evidence may not be of much assistance in delimiting the genus, although it may be useful as an indication of relationships between the species. It is held that chromosome morphology, critically ascertained, may perhaps offer greater possibilities in generic definitions than chromosome numbers; but where the chromosomes are of very small size, or present in large numbers, this approach tends to be beset with difficulties. The general conclusions reached are that chromosome study provides, for taxonomic purposes, essentially the same kind of evidence as that derived from other parts of the plant, and that cytogenetics may aid substantially in the construction of the kind of generic classification that most adequately reflects the evolutionary relationships of the component species and of the families to which they belong. The respective contributions of embryological and plant geographical studies to an understanding of genera are also adequately discussed. 'The general effect of this collection of papers is to bring before the reader a fund of valuable and interesting information on many aspects of botany as they relate to a central and traditional theme.

\section{STUDIES IN SOCIAL ANTHROPOLOGY}

$\mathrm{S}^{\mathrm{s}}$ IR JAMES FRAZER, a classical scholar and a type of prehistorian more than he was a historian, was interested in what he termed "the general laws which have regulated human history in the past, and which if nature is uniform may be expected to regulate it in the future". The lecture by Prof. Max Gluckman on "Rituals of Rebellion in South-East Africa"* is the Frazer Lecture for 1952, and that by Prof. M. Fortest, which is his inaugural lecture as William Wyse professor of social anthropology in the University of Cambridge, is in agreement with Frazer, Haddon, Malinowski and Radcliffe-Brown that there are regularities independent of period and place in social organization and culture, defined as morals, law, custom and socially acquired capabilities and habits. Therefore, it is appropriate to consider here Frazer on the topic of uniformities about man's natural status.

Frazer was distinctly uneritical in his acceptance of what missionaries wrote about primitive culture and personality. For example, of the Kai Papuans of the 1899-1902 and earlier period, Charles Keysser remarked that they were fearful of the military power of an enemy, and parsimonious about making payments to allies whom they needed to mount successful offensives, preferably with superior force, against some neighbouring small group of Kai they termed sorcerers. On account of these traits of character, the leaders of the small territorial groups into which the natives were divided before their conquest sometimes delayed launching attacks against sorcerers for some interval of time after their fellows' deaths which they regarded as provocations. They attributed droughts, inroads of garden pests, bad luck in hunting and epidemics of colds in the head, which sometimes supervened in time of delay and of unreadiness for mounting attacks against sorcerers, to the wrath of the spirits of their kindred, which they worshipped in a manes cult, but whose deathsto discuss dead men as if they were spirits-had not

* Rituals of Rebellion in South-East Africa. (The Frazer Lecture, 1952.) By Prof. Max Gluckman. Pp. ii +36 . (Manchester University Press, 1954.) 3s. 6d.

† Social Anthropology at Cambridge since 1900: an Inaugural Lecture. By P'rof. M. Fortes. Pp. 47. (Cambridge University Press,
1953. 6 . 
provoked prompt retaliatory (that is, offensive) attacks against sorcerers.

The Kai thought that the greatest love and the deepest sympathy which they could display to their dead was to retaliate for their dead against sorcerers, and so help their spirits to attain rest and peace in the other world, which in their belief was an underworld to which the spirits went about the time the flesh decayed on the skeleton. If the Kai had not feared the ghosts of their fellows more than they feared the military power of an enemy, and more than they valued their savings of shell ornaments, boars' tusks and pork, which they expended to procure allies, they would not have launched their offensives against sorcerers, but would have remained peaceful. The Kai of the 1902-11 period under German administration up to the date of Keysser's publication in "Deutsch Neu Guinea" (edited by R. Neuhauss) were peace-loving by nature, and in this respect considered to be comparable to Germans.

Keysser's views on the topic of Papuan tribal culture and personality require critical analysis. Sir James Frazer, however, searching for general laws of prehistories, uniformities of human nature and expected regularities of histories, accepted Keysser without question, attributed homicides in connexion with sorcery once held justifiable by Australian aboriginals, some Melanesians and some Papuans to ghost fear, and compared primitive warring about pretexts proper to a general belief in magic with European wars over religious differences. In his work "The Belief in Immortality" (Vol. 1) he summed up this view of uniformity in human nature, and of general laws which have prevailed in human history, with the remark: "The state of war, which normally exists between many, if not most, neighbouring tribes, springs in large measure directly from their belief in immortality; since one of the commonest motives for hostility is a desire to appease the angry ghosts of friends, who are supposed to have perished by the baleful arts of sorcerers in another tribe, and who, if vengeance is not inflicted on their real or imaginary murderers, will wreak their fury on their undutiful fellow tribesmen. Thus the bolief in immortality has not merely coloured the outlook of the individual upon the world ; it has also deeply affected the social and political relations of humanity in all ages; for the religious wars and persecutions, which distracted and devastated Europe for centuries, were only the civilized equivalents of the battles and murders which the fear of ghosts has instigated amongst almost all races of savages of whom we possess a record".

The remark is an instance of error in an attempted explanation of miscellaneous facts in a formula about motives and character. Another instance of the kind is the thesis of "The Golden Bough", which discusses in odd places the homicides of divine kings by their successors, with no good reduction of miscellaneous facts to a formula including the affair of Cromwell and Charles I, or the homicide of a Hapsburg in Serbia in 1914. Ruth Benedict and Margaret Mead have also written anthropological works in the culture and personality field; but, as Bernard Notcutt notes in his recent work entitled "The Psychology of Personality", what the subject needs at the moment is some kind of discipline. Papuan culture, although it varied somewhat in different areas of New Guinea, probably did not vary in an entirely disorderly manner; and partly with an intention of testing Margaret Mead's theories about Papuan character, we studied bow-and-arrow fighting over sorcery among the Kamano Papuans in 1935. The Kamano said upon question in 1951-52 about motive that they had not thought that the spirits of their dead needed their former actions against sorcerers of them; they had not maintained a doctrine that ghosts required the deaths of sorcerers; and they had not feared ghostly commination for delay in launching offensives, although they had not delayed. The provoking natural deaths which had preceded the fighting incidents we had seen in 1935 had taken place one, five days before an incident broke out, and one nine days before another. We investigated antecedents and sequences in detail; but there is no space to discuss them here.

Nature, when known, is a critic of such gross imputations of responsibility for the purpose of punishment or of dispute of land tenure as may be implied by the belief in sorcery as the cause of death, and one may be interested in the truth or error of statements claiming to state uniformities about man's natural status without expectation that men will return to prehistoric conditions. Prof. Fortes's inaugural lecture takes issue with a view expounded by Evans-Pritchard in his "Social Anthropology" that 'social systems' are not 'natural systems' and that therefore social anthropology and sociology need not have as their aim statements of uniformities about man's natural status. Prof. Gluckman discusses first-fruit rituals of the agricultural year among the Zulu and the Swazi. The thesis is that ritual expresses the tensions of the social organization. A similar thesis is maintained by Evans-Pritchard in his Frazer Lecture for 1948, "The Divine Kingship of the Shilluk" of the Nilotic Sudan, with a note that there was no knowledge that actual regicide had occurred often in their unwritten past.

\section{R. F. Fortune}

\section{THE HANFSTAENGL COLOUR COLLOTYPE REPRODUCTIONS}

7 HE colour reproductions of old and modern masters, printed and published by the firm of Hanfstaengl of Munich, which since the beginning of the War were unobtainable in many countries, are happily once more available. The firm of Hanfstaengl is well known for the high quality and fidelity of its reproductions ; moreover, it has covered a very wide range of original paintings and schools-from the classics to the impressionists and expressionists.

The Pallas Gallery, Ltd., 28B, Albemarle Street, London, W.1, are sole agents in Great Britain and the British Commonwealth for Messrs. Hanfstaengl, and has recently issued a well-illustrated catalogue of the 150 -odd prints now available. The prices are $42 s$., $52 s .6 d ., 63 s$. , and $73 s .6 d$. ; and some four-colour prints (20 in. by 16 in.) may be obtained at $21 s$. each.

Among the various artists represented are (with examples given in brackets) : Italian School (Titian, Botticelli); German School (Dürer, Holbein) ; Flemish and Dutch Schools (van Dyck, Rubens); French Impressionists (Renoir, Monet); Post-Impressionists (Cézanne, Gauguin, van Gogh); School of Paris (Matisse, Picasso); Kokoschka; German Expressionists (Marc) ; German Romantics (von Hess) ; and a collection of decorative pictures including landscapes (Heffner, Mercker), animal paintings (Olszewski, 